\title{
Experimental Study of Natural Convective Heat Transfer from Vertical Rectangular Fin Array at Different Angle of Inclination
}

\author{
S. V. Kadbhane and D. D. Palande \\ Mechanical Engg. Dept., SPPU, MCOERC, Nasik, Maharashtra, India \\ Accepted 15 June 2016, Available online 20 June 2016, Special Issue-5 (June 2016)
}

\begin{abstract}
Steady state natural convective heat transfer from vertical rectangular fin array with isothermal and constant heat flux conditions is studied experimentally. Natural convective heat transfer from rectangular vertical fin array can be enhanced by optimizing the geometrical parameters such as fin length, width, height, and spacing. Also orientation of fin array, affects the natural convective heat transfer rate. An experimental set up was constructed to test 25 different fin arrays. Fin length and thickness were kept constant at $L=200 \mathrm{~mm}$ and $t=2.5 \mathrm{~mm}$ respectively. Fin spacing was varied from 5.5 to $14.5 \mathrm{~mm}$ and height was varied from 5 to $25 \mathrm{~mm}$. Five different heat inputs ranging from $15 \mathrm{~W}$ to $75 \mathrm{~W}$ were supplied to all configurations. Experimentation revealed that optimization of geometrical parameters affects convective heat transfer rate. Effect of fin spacing on heat transfer rate was found more dominant than other geometrical parameters. It was observed that as fin spacing was increased, convective heat transfer rate also increases, reaches to maximum at a certain value of spacing known as optimum fin spacing and then decreases with further increase in spacing. Also it was observed that natural convective heat transfer rate is maximum for vertical orientation and it goes on decreasing as we incline fin array from vertical to horizontal.
\end{abstract}

Keywords: Natural convection, enhancement in heat transfer rate, geometrical parameters, angle of inclination, optimum fin spacing.

\section{Introduction}

In many engineering applications, during their operation heat is generated. If this generated heat is not dissipated rapidly to surrounding atmosphere, it may cause rise in temperature of the system components (Naidu, et al, 2010). This causes serious overheating problems in system and leads to system failure, so the generated heat within the system must be rejected to its surrounding for its efficient working (Burak, et al, 2007). Especially important in modern electronic systems, in which the packaging density of circuits can be high, engines, industrial equipment and a variety of mechanical devices, to overcome this problems fins as effective passive cooling device for thermal systems are suitable (Burak, 2005).

Simple and easiest way of rejection of heat from system to its surrounding is using fins andis used in various engineering applications successfully. The optimal combination of geometry and orientation of the finned surface are required to achieve the desired rate of heat dissipation (Tari, et al, 2013). Mostlyrectangular types of fins are used because of their low production cost, simple in construction, effectiveness, high cooling capability. It is possible to

${ }^{*}$ Corresponding author: S. V. Kadbhane increase the heat transfer coefficient, $h$ by forcing the air flow over the fins by using fans, but by using this option cost should be high and requires more space for to operate fans, therefore forced convection is not always preferable. Since the use of extended surfaces is often more economical, convenient and trouble free, most proposed application of increasing surface area is adding fins to the surface in order to achieve required rate of heat transfer(Burak, 2005). So, heat transfer by natural convection for dissipating unwanted heat from the fins is always better than forced convection. In order to increase the total heat transfer area, more fins added to the base. The number of the fins and fin optimum spacing should be calculated because it is observed that adding more fins to base, decreases the distance between the adjacent fins, because of this resistance to air flow and interference between boundary layers which affect in decrease the heat transfer coefficient (Tari et al, 2013).

\section{Experimental Setup}

\subsection{Methodology}

While performing experiments power input will be varying through dimmer stat. Power input is varied from $15 \mathrm{~W}$ to $75 \mathrm{~W}$. After attaining steady state base 
plate temperatures is measured. In order to decide whether the fin array is at steady state or not, the thermocouple readings are taken after half an hour interval and this condition can be assumed when difference between successive readings is less than $0.5^{\circ} \mathrm{C}$. The base plate temperature $\mathrm{T}_{\mathrm{w}}$, the ambient temperature $\mathrm{T}_{\mathrm{a}}$ and the power input $\mathrm{P}$ to heater is recorded at steady state. Testing procedure mentioned above is repeated for various heater inputs $15 \mathrm{~W}$ to 75 W.After all of the flow properties are known, $\mathrm{Ra}$ and $\mathrm{Nu}$ can be found as follows,

$$
\begin{gathered}
R a=\frac{g \times \beta \times L c^{3} \times(T w-T a)}{v \times \alpha} \quad h=\frac{Q c}{A s \times(T w-T a)} \\
N u=\frac{h \times L c}{K}
\end{gathered}
$$

Where Lc is the characteristic length (length of the plate).

Theoretical Nusselt number can be calculated using following correlations :

1] McAdam's correlation

$$
\mathrm{Nu}=0.59 \times R a^{0.25}
$$

2] Churchill and Chu's first correlation

$$
\mathrm{Nu}=\left[0.825+\frac{0.387 \times R a^{1 / 6}}{\left[1+\left(\frac{0.492}{P r}\right)^{9 / 16}\right]^{8 / 27}}\right]^{2}
$$

3] Churchill and Chu's Second correlation

$$
\mathrm{Nu}=0.68+\frac{0.67 \times R a^{1 / 4}}{\left[1+\left(\frac{0.492}{P r}\right)^{9 / 16}\right]^{4 / 9}}
$$

4] Churchill and Usagi's correlation

$$
\mathrm{Nu}=\frac{0.67 \times R a^{1 / 4}}{\left[1+\left(\frac{0.492}{P r}\right)^{9 / 16}\right]^{4 / 9}}
$$

\subsection{Experimental Equipment and Instrumentation}

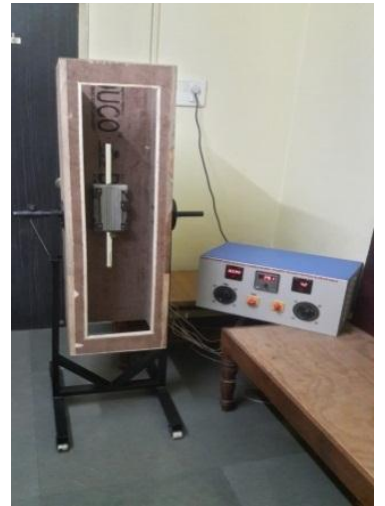

(a) Vertical Orientation

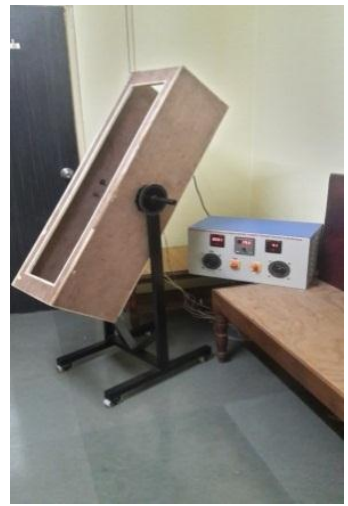

(b) Inclined orientation
Fig. 1 Experimental Set-up

2.3 Experimental setup consists of following components

1. MS frame

2.Aerated concrete block

3. Heater plate

4. Thermocouples

5. Aluminum fins

\section{Voltmeter}

7. Ammeter

8. Dimmer stat

9. Multi point temperature indicator
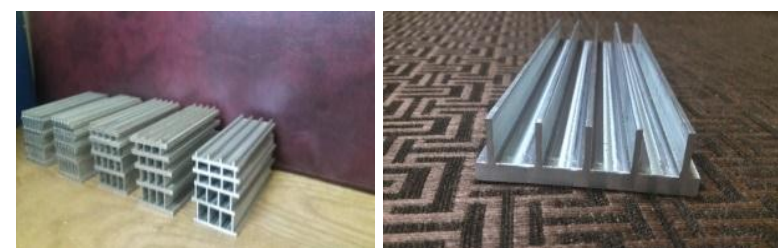

Fig.2 Fin Models

Table 1 Dimension of setup

\begin{tabular}{|c|c|}
\hline Component & Dimension $(\mathrm{mm})$ \\
\hline Frame & $1200 * 300 * 300$ \\
\hline Concrete & $210 * 120 * 50$ \\
\hline Heater & $200 * 75$ \\
\hline
\end{tabular}

\subsection{Comparison of Experimental Nusselt number with Theoretical Correlations}

Four theoretical correlations considered to validate experimental value are :

1] Churchill and Chu's first correlation

$$
\mathrm{Nu}=\left[0.825+\frac{0.387 \times R a^{1 / 6}}{\left[1+\left(\frac{0.492}{P r}\right)^{9 / 16}\right]^{8 / 27}}\right]^{2}=49.75779
$$

2] Churchill and Chu's second correlation

$$
\mathrm{Nu}=0.68+\frac{0.67 \times R a^{1 / 4}}{\left[1+\left(\frac{0.492}{P r}\right)^{9 / 16}\right]^{4 / 9}}==43.94409
$$

3] Mac Adams correlation

$$
\mathrm{Nu}=0.59 \times \mathrm{Ra}^{1 / 4}=49.7088
$$

4] Churchill and Usagi's correlation

$\mathrm{Nu}=\frac{0.67 \times R a^{1 / 4}}{\left[1+\left(\frac{0.492}{P r}\right)^{9 / 16}\right]^{4 / 9}}=43.2609$

5] $\mathrm{Nu}$ by experimentations $=40.78$

Sample results of the analysis and the comparison of Nusselt number are given in Table 2.

Table 2 Comparison of Nusselt Number

\begin{tabular}{|c|c|c|c|c|}
\hline Ra & Nu Expt. & Nu1 & Nu2 & Nu3 \\
\hline 30370232.93 & 34.28 & 42.93 & 38.82 & 38.14 \\
\hline 44365777.11 & 38.66 & 47.94 & 42.59 & 41.91 \\
\hline 50387814.2 & 40.78 & 49.75 & 43.94 & 43.26 \\
\hline
\end{tabular}




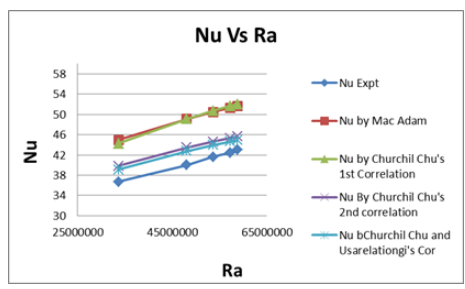

Fig.3 Comparison of Nusselt Number of Present Study with Theoretical Correlation

As shown in Table 2 and Fig. 3 Experimental Nusselt Number is compared with theoretical Nusselt number obtained from four theoretical correlations.

\section{Scale Analysis}

The main purpose of it is to obtain a relation for the optimum fin spacing that maximizes the heat transfer rate from vertical rectangular fins extending perpendicularly out of a vertical rectangular base. For the scale analysis, the procedure applied for rectangular fin array in Ref. (Burak, 2005) was adopted for the current geometry.

\subsection{The Small-s Limit}

In small-s limit, the boundary layer interferences occur immediately after air enters to the channels of the fin array, and therefore, the flow through each channel of the array can be assumed as fully developed channel flow. The total heat transfer rate from a single channel is given by(Burak, 2005):

$\dot{Q} \mathrm{c}_{\text {single channel }}^{(1)}=\dot{m} \cdot \mathrm{C}_{\mathrm{p}} \cdot \Delta \mathrm{T}$

Where $\dot{m}$ is the mass flow rate through a single channel, $\mathrm{C}_{\mathrm{p}}$ is the specific heat of air at constant pressure and $\Delta \mathrm{T}$ is order-of-magnitude of the temperature difference. From the scale analysis of continuity and momentum equations, mass flow rate can be written as:

$\dot{m} \approx \frac{\rho * g * \beta * s^{3} * \Delta T}{v} . \mathrm{H}$

If the number of channels (or the fins) is defined as $\mathrm{n}=$ $\mathrm{W} / \mathrm{s}(\mathrm{W} / \mathrm{s} \gg 1)$, then the total heat transfer rate fromthe fins may be expressed as:

$\dot{m} \approx \frac{\rho * g * \beta * s^{3} * \Delta T}{v} . \mathrm{H} \cdot \mathrm{C}_{\mathrm{p}} \cdot \Delta \mathrm{T} \cdot \frac{W}{s}$

Where $\dot{Q}_{c}^{(1)}$ is the difference between total convection heat transfer rate $\dot{Q}_{c}$, and the convection heat transfer from the base-plate, $\left(\dot{Q}_{\mathrm{o}}\right)_{\mathrm{c}}$, as:

$\dot{Q}_{c}^{(1)}=\dot{Q}_{c}-\left(\dot{Q}_{\mathrm{o}}\right)_{\mathrm{c}}$

In Eq. (3.4) $\dot{Q}_{\mathrm{c}}$ and ( $\left.\dot{Q}_{\mathrm{o}}\right)_{\mathrm{c}}$ are evaluated at the same baseto-ambient temperature difference. Introducing the thermal diffusivity, $\alpha$ into Eq. (3.3), the following equation is obtained as:

$\dot{Q}_{\mathrm{c} 1} \approx \frac{g * \beta * s^{3} * \Delta T}{v * \alpha}$. H .k.C. $\cdot \Delta \mathrm{T} \cdot \frac{W}{s}$

As seen from Eq. (3.5), in the small-s limit, the total heat convection heat transfer rate is directly proportional with $\mathrm{s}^{2}$.

A dimensionless form of Eq. (3.5) may be obtained as :

$$
\frac{\dot{Q}_{c}^{(1)} \cdot \frac{s}{W}}{\mathrm{H} \cdot \mathrm{k} \cdot \Delta \mathrm{T}} \approx \frac{g * \beta * s^{3} * \Delta T}{\nu * \alpha}
$$

The right hand side of Eq. (3.6) can be written in terms of Rayleigh number based on fin spacing as :

$\frac{Q_{\mathrm{c} 1}}{\text { n. H. k. } \Delta \mathrm{T}} \approx \mathrm{Ra}_{\mathrm{s}}$

\subsection{The Large-s Limit}

In the large-s limit, the fin spacing, $s$ is sufficiently greater than the boundary layer thickness, and hence, the boundary layers develop without any interference in the channel. Under boundary layer flow conditions, the total convection heat transfer rate from a single fin can be expressed as(Burak, 2005):

$\dot{Q} \mathrm{c}_{\text {single fin }}^{(2)}=2 \cdot$ h. A.$\Delta \mathrm{T}$

Where, $\mathrm{h}$ is the heat transfer coefficient over single fin, $\mathrm{A}$ is the area of single fin and $\Delta \mathrm{T}$ is order-of-magnitude of the temperature difference.

Applying the scale analysis to Navier-Stokes equations and energy equation, heat transfer coefficient can be written as:

$h \approx\left[\frac{\rho * g * \beta * L^{3} * \Delta T}{\nu * \alpha}\right]^{0.25} \cdot \frac{k}{L}$

If the area of the single fin, $\mathrm{A}=\mathrm{H} \cdot \mathrm{L}$ and the number of fins, $n=W /$ sare introduced into Eq. (3.9), the total heat transfer rate from the fins can be expressed as:

$\dot{Q}_{c}^{(2)} \approx 2 \cdot\left[\frac{g * \beta * L^{3} * \Delta T}{v * \alpha}\right]^{0.25} \cdot \frac{k}{L}$. H. L.$\Delta \mathrm{T} \cdot \frac{W}{s}$

where $\dot{Q}_{c}^{(2)}$ is the difference between total convection heat transfer rate, $\dot{Q}_{c}$, and the convection heat transfer from the base-plate, $(\dot{Q} \circ) \mathrm{c}$, as :

$\dot{Q}_{c}^{(2)}=\dot{Q}_{c}-(\dot{Q} \mathrm{o}) \mathrm{c}$

Eq. (3.11) can be written in the following form as:

$\dot{Q}_{c}^{(2)} \approx 2 \cdot\left[\frac{g * \beta * L^{3} * \Delta T}{v * \alpha}\right]^{0.25} \mathrm{k} . \mathrm{H} . \Delta \mathrm{T} \cdot \frac{W}{s}$

As seen from Eq. (3.12), in the large-s limit, the convection heat transfer rate from the fins is inversely proportional with s..

A dimensionless form of Eq. (3.12) may be obtained as:

$\frac{\dot{Q}_{c}^{(2)} \cdot \frac{s}{W}}{\mathrm{H} \cdot \mathrm{k} \cdot \Delta \mathrm{T}} \approx 2 \cdot\left[\frac{g * \beta * L^{3} * \Delta T}{v * \alpha}\right]^{0.25} \mathrm{k} \cdot \mathrm{H} \cdot \Delta \mathrm{T} \cdot \frac{W}{s}$

The right hand side of Eq. (3.13) can be written in terms of Rayleigh number based on fin length as:

$\frac{\dot{Q}_{c}^{(2)} \cdot}{\text { n. k. H. } \cdot \Delta \mathrm{T}} \approx 2^{*} \mathrm{Ra}^{0.25}$

The trends of two curves reveal that the intersection of curves must give the maximum rate of total convection heat transfer which indicates the optimum fin spacing. As shown in Figure 4, the maximum occurs in the vicinity of the intersection (Burak, 2005): 


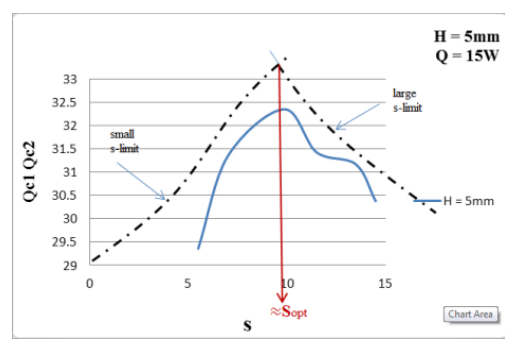

Fig. 4 Asymptotic Plot for Extreme Limits

Correlation obtained for optimum fin spacing is:

$\frac{s_{\text {opt }}}{L}=4.15 \mathrm{Ra}^{-0.25}$

\section{Results and Discussion}

The experimental data obtained from 25 different fin configurations is considered. These all results are used to reveal the effect of said geometric parameters, orientation of finarray and heat input on the steady state heat dissipation from finned surfaces.

\subsection{Effect of temperature difference over convective heat transfer rate for different heat input}

The convection heat transfer rates from fin arrays are plotted as a function of temperature difference for fin lengths, $\mathrm{L}=200 \mathrm{~mm}$. Orientation of fin array is vertical i.e. $\theta=0$. Heat Input is varied. Effect is verified for five different sets, i.e. for fin spacing of $5.5 \mathrm{~mm}, 7 \mathrm{~mm}$, $9.85 \mathrm{~mm}, 13.5 \mathrm{~mm}$ and $14.5 \mathrm{~mm}$. In each set, fin height is varied as $\mathrm{H}=5 \mathrm{~mm}, 10 \mathrm{~mm}, 15 \mathrm{~mm}, 20 \mathrm{~mm}, 25 \mathrm{~mm}$.

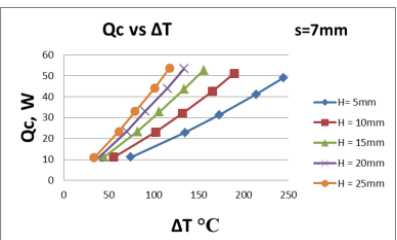

(a)

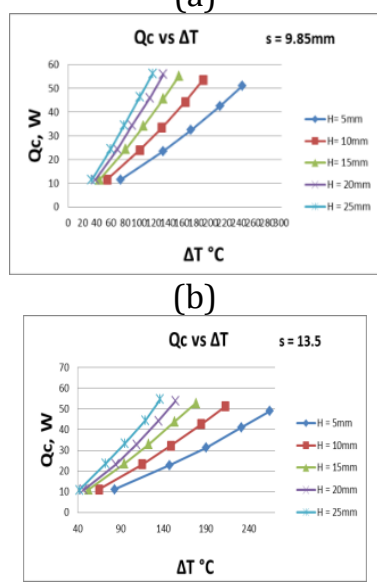

(c)

Fig.5(a), (b), (c) Variation of Convection Heat Transfer rate with Temperature Difference at a Fin Length of $\mathrm{L}=200 \mathrm{~mm}$ and Fin spacing of $\mathrm{s}=7,9.85,13.5 \mathrm{~mm}$
As observed in fig 5 (a) (b) and (c), nature of curve indicates that at a constant height and spacing convective heat transfer rate increases as temperature difference between base temperature and ambient temperature increases. At a given fin spacing, temperature difference between base temperature and ambient temperature decreases as fin height increases. Effect of fin spacing was observed to be more dominant than height on variation of convective heat transfer with respect to temperature difference.

\subsection{Effect of angle of inclination over heat transfer rate for different fin height and heat input}

The convection heat transfer rates from fin arrays are plotted as a function of angle of inclination for fin lengths, $\mathrm{L}=200 \mathrm{~mm}$ and fin spacing, $\mathrm{S}=9.85 \mathrm{~mm}$. Effect is verified for fin height $\mathrm{H}=5 \mathrm{~mm}, 15 \mathrm{~mm}, 25 \mathrm{~mm}$. Angle of inclination is varied as $\theta=0^{\circ}, 30^{\circ}, 45^{\circ}, 60^{\circ}, 90^{\circ}$. Heat Input is varied as $15 \mathrm{~W}, 30 \mathrm{~W}, 45 \mathrm{~W}, 60 \mathrm{~W}, 75 \mathrm{~W}$.

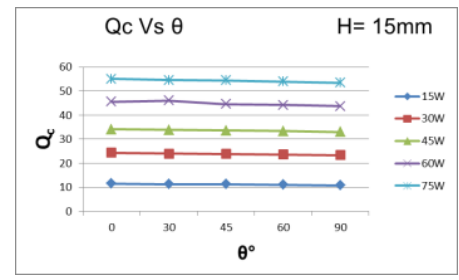

Fig.6Variation of Convection Heat Transfer rate with Heat Input at a Fin Length of $\mathrm{L}=200 \mathrm{~mm}$ and Fin Height $\mathrm{H}=15 \mathrm{~mm}$

As observed in fig 6, the convection heat transfer rate from fin arrays depends on inclination of heat sink Convective heat transfer decreases from vertical position $\left(0^{\circ}\right)$ to horizontal position $\left(90^{\circ}\right)$.

4.3 Effect of angle of inclination over base temperature for different heat input and different fin height

As shown below effect of angle of inclination $\theta$ over base temperature $\mathrm{T}_{\mathrm{w}}$ is observed for fin length of $\mathrm{L}=$ $200 \mathrm{~mm}$ and fin spacing of $\mathrm{s}=9.85 \mathrm{~mm}$. Angle of inclination is varied as $\theta=0^{\circ}, 30^{\circ}, 45^{\circ}, 60^{\circ}, 90^{\circ}$. Effect was observed for Heat Input of $15 \mathrm{~W}$.

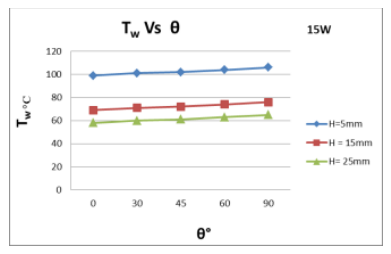

Fig 7Variation of Base Temperature with Angle of Inclination at a Fin Length of $\mathrm{L}=200 \mathrm{~mm}$ and Heat Input of $15 \mathrm{~W}$

From fig.7, it was observed that value of base temperature increases as angle of inclination increases. 
4.4 Effect of angle of inclination over heat transfer rate for different fin height

The effect of fin height on convection heat transfer rate at different angle of inclination was observedfor heat input $45 \mathrm{~W}$. Fin spacing is $\mathrm{s}=9.85 \mathrm{~mm}$. Effect is verified for fin height $\mathrm{H}=5 \mathrm{~mm}, 10 \mathrm{~mm}, 15 \mathrm{~mm}, 20 \mathrm{~mm}, 25 \mathrm{~mm}$. Angle of inclination is varied as $\theta=0^{\circ}, 30^{\circ}, 45^{\circ}, 60^{\circ}$, $90^{\circ}$.

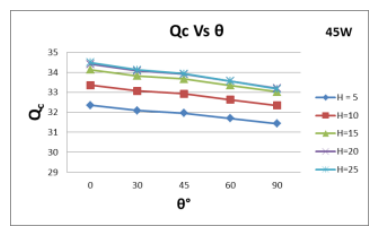

Fig.8 Variation of Convection Heat Transfer rate with angle of inclination at a Fin Length of $\mathrm{L}=200 \mathrm{~mm}$ and Heat input $Q_{\text {in }}=45 W$.

As observed in fig.8, Convective heat transfer rate decreases as angle of inclination increases for a constant fin height.

\subsection{Effect of fin spacing on convective heat transfer rate for different heat input}

Effect of fin spacing on convective heat transfer rate is observed. Heat input is varied. At each heat input fin height is varied as $5 \mathrm{~mm}, 10 \mathrm{~mm} 15 \mathrm{~mm}, 20 \mathrm{~mm}, 25 \mathrm{~mm}$. At each fin height, fin spacing is varied as $5 \mathrm{~mm}, 7.5 \mathrm{~mm}$, $9.85 \mathrm{~mm}, 13.5 \mathrm{~mm}$, and $14.5 \mathrm{~mm}$.

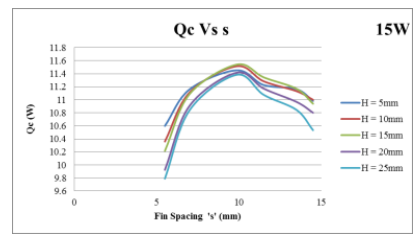

Fig.9 Variation of Convection Heat Transfer rate at a Fin Length of $\mathrm{L}=200 \mathrm{~mm}$ and Heat input $\mathrm{Q}_{\mathrm{in}}=15 \mathrm{~W}$

From fig.9, it was observed that convective heat transfer rate first increases with increase in spacing upto certain limit and then decreases with further increase in spacing, and reaches to maximum at a certain value of spacing i.e. at an optimum value of spacing.Convective heat transfer rate was maximum between spacing of $9 \mathrm{~mm}$ and $11 \mathrm{~mm}$.Hence it was found that optimum fin spacing lies between $9 \mathrm{~mm}$ and $11 \mathrm{~mm}$.

\subsection{Effect of fin spacing on convective heat transfer rate for different $\Delta T\left(T_{w}-T_{a}\right)$}

Effect of fin spacing on convective heat transfer rate was observed Heat input was varied. At each value of fin heights i.e. $5 \mathrm{~mm}, 15 \mathrm{~mm}, 25 \mathrm{~mm}$ heat input was varied. At varying heat input at each value of $\Delta \mathbf{T}\left(\mathbf{T}_{\mathbf{w}}-\right.$
$\mathbf{T}_{\mathbf{a}}$ ), fin spacing was varied as $5 \mathrm{~mm}, 7.5 \mathrm{~mm}, 9.85 \mathrm{~mm}$, $13.5 \mathrm{~mm}, 14$

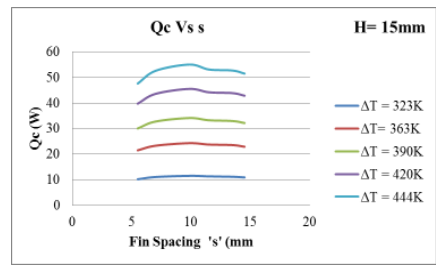

Fig.10 Variation of Convection Heat Transfer rate with spacing at a Fin Length of $\mathrm{L}=200 \mathrm{~mm}$ and Fin Height, $\mathrm{H}=15 \mathrm{~mm}$

As observed from fig. 10, Convective heat transfer rate first increases with increase in spacing upto certain limit and then decreases with further increase in spacing, and reaches to maximum at a certain value of spacing i.e. at an optimum value of spacing. Itwas maximum between spacing of $9 \mathrm{~mm}$ and $11 \mathrm{~mm}$.Hence it was found that optimum fin spacing lies between $9 \mathrm{~mm}$ and $11 \mathrm{~mm}$.

\section{Conclusions}

(1) Natural convective heat transfer rate from vertical rectangular fin array is a function of geometrical parameters and angle of inclination. At a constant fin length, fin spacing and fin height affects the convective heat transfer rate most.

(2) It was found that natural convective heat transfer rate first increases with increase in spacing upto certain limit, reaches to maximum at a certain value of spacing i.e. at an optimum value of spacing and then decreases with further increase in spacing, and For present study value of optimum fin spacing was found between $9 \mathrm{~mm}$ to $11 \mathrm{~mm}$.

(3) Experimental results obtained for optimum fin spacing were validated by scale analysis. Same results were obtained by scale analysis.

(4) Also it was observed that natural convective heat transfer rate is maximum for vertical orientation of fin array and it goes on decreasing as we incline fin array from vertical to horizontal. Therefore for better heat transfer vertical rectangular fin array is preferred than horizontal.

\section{References}

B. Yazicioglu, (2005), Performance of rectangular fins on a vertical Base in free convection heat transfer, A Thesis Submitted to The Graduate School of Natural And Applied Sciences of Middle East Technical University.

K. M.Cakar, (2009), Numerical investigation of natural convection from vertical plate finned heat sinks, A Thesis Submitted to The Graduate School of Natural And Applied Sciences of Middle East Technical University.

I. Tari, M. Mehrtash, (2013), Natural convection heat transfer from inclined plate-fin heat sinks, International Journal of Heat and Mass Transfer, vol.56, pp. 574 - 593.

I. Tari, M. Mehrtash, (2013), A correlation for natural convection heat transfer from inclined plate-finned heat 
sinks,Applied Thermal Engineering, vol.51, pp. 1067 1075.

B. Yazicioglu, H.Yuncu, (2007), Optimum fin spacing of rectangular fins on a vertical base in free convection heat transfer, Journal of heat and mass transfer, vol.44, pp. 11 21.

H. Yuncu, G. Anbar, (1998), An experimental investigation on performance of rectangular fins on a horizontal base in free convection heat transfer, Heat Mass Transfer, vol.33, pp. 507-514.

S. Baskaya , M. Sivrioglu, M. Ozek, (2000), Parametric study of natural convection heat transfer from horizontal rectangular fin arrays, Int. J. Thermal Sci., vol.39, pp. 797 805.

S. V. Naidu, V. D. Rao, B. G. Rao, A. Sombabu, B. Sreenivasulu, (2010), Natural convection heat transfer from fin arrays experimental and theoretical study on effect of inclination of base on heat transfer, ARPN Journal of Engineering and Applied Sciences, vol.5,no.9.

B. Yazicioglu, H. Yuncu, (2009), A correlation for optimum fin spacing of vertically-based rectangular fin arrays subjected to natural convection heat transfer", J. of Thermal Science and Technology, vol. 29 no.1, pp. 99-105.

F. Harahap, D.Setio, (2001), Correlations for heat dissipation and natural convection heat-transfer from horizontallybased, vertically-finned arrays, Applied Energy, vol.69, pp. 29-38.

F. Harahap, H. Lesmana, (2006), Measurements of heat dissipation from miniaturized vertical rectangular fin arrays under dominant natural convection conditions", Heat Mass Transfer, vol.42, pp. 1025-1036.

V. Wankar, S. G. Taji, (2012), Experimental Investigation of flow pattern on rectangular fin array under natural convection, International Journal of Modern Engineering Research, vol.2,no.6, pp. 4572-4576.

M. J. Saad, (2009), Effect Orientation on Performance of Longitudinal (Trapezoidal) Fins Heat Sink Subjected to Natural Convection, Anbar Journal of Engineering Sciences, vol. 2, no.2.
H. Wadhah, A. Razzaq, Al- Doori, (2011), Enhancement of natural convection heat transfer from the rectangular fins by circular perforations, International Journal of Automotive and Mechanical Engineering, vol.4, pp. 428 436.

M. Fahiminia, M. M. Naserian, H. R.Goshayeshi, D. Majidian, (2011), Investigation of Natural Convection Heat Transfer Coefficient on Extended Vertical Base Plates, Energy and Power Engineering, vol. 3, pp. 174-180.

S. Mahmoud, R. Al-Dadah, D. K.Aspinwall, S. L.Soo, H. Hemida, (2011), Effect of micro fin geometry on natural convection heat transfer of horizontal microstructures, Applied Thermal Engineering, vol.31, pp. 627-633.

S. S. Kharche, H. S. Farkade, (2012), Heat Transfer Analysis through Fin Array by Using Natural Convection, International Journal of Emerging Technology and Advanced Engineering., vol.2, no.4, pp. 595 - 598

S. S. Sane, G. V.Parishwad, (2008), Computational analysis of horizontal rectangular notched fin arrays dissipating heat by natural convection, 5th European Thermal-Sciences Conference, The Netherlands.

T. H. Kim, K. H. Do, D. K. Kim, (2011), Closed form correlations for thermal optimization of plate-fin heat sinks under natural convection, International Journal of Heat and Mass Transfer, vol. 54, pp. 1210-1216.

D. K. Kim, (2012), Thermal optimization of plate-fin heat sinks with fins of variable thickness under natural convection, International Journal of Heat and Mass Transfer, vol. 55, pp. 752-761

M. Dogan, M. Sivrioglu, (2010), Experimental investigation of mixed convection heat transfer from longitudinal fins in a horizontal rectangular channel, International Journal of Heat and Mass Transfer, vol.53, pp. 2149-2158.

S. A. Nada, (2007), Natural convection heat transfer in horizontal and vertical closed narrow enclosures with heated rectangular finned base plate, International Journal of Heat and Mass Transfer, vol.50, pp. 667-679.

H. T. Chen, S. T. Lai, L. Haung, (2013), Investigation of heat transfer characteristics in plate-fin heat sink, Applied Thermal Engineering, vol.50, pp. 352-360. 